\title{
DEVELOPING EVALUATION INSTRUMENT OF READING FOUR TEST FOR UNIVERSITY STUDENT
}

\author{
Refai
}

Muhammadiyah University of Metro

\begin{abstract}
The objective of the study was to develop the evaluation Instrument of reading four test. The development of such instrument is a valuable effort to measure the students' mastery of the reading skill and to improve the quality of the evaluation instrument which is produced by the teacher. Before the teacher develop the reading evaluation instrument, he had cultivated the previous test instrument to analyze the weakness and the strength of the implemented test instrument. After that, the teacher started to develop a prototype which has been modified by the teacher himself. Then, he administered the first try out to the English students of semester VII and collecting some inputs and critics of the modified reading test instrument after the students finished doing the test. The result of the test together with the students' critics and inputs were used to rebuild the reading test intrument better. At last, the teacher has developed the evaluation instrument of reading test for students of semester VII in Muhammadiyah University of Metro
\end{abstract}

Key Words: Reading, developing.

As language is a mean of communication to mankind, thus applying languages, everyone is very important since it may exchange information among them. In this global era, communication to get information is not only limited by the same culture and nation, but todays it has been crossing the line. Communication acrosses the world is bridged by international languaes, which one of them is English. Since
English is an international language in the world, people are more to communicate globally in English. Communication of English is occured in business, education and other aspects of life.

In the world of Education, English is one of the subjects which are learnt and taught in the classes. The mastery of English will not be completed by accredited the 
language elements; vocabulary, structure, etc, and language skills; they are listening, speaking, reading and writing. There are four capabilities that are required to master by the English learners; they are listening, speaking, reading and writing. As reading skill involves numerous complex abilities which will come together in order to the readers. One characteristic of the good readers is that he/she is able to make prediction of the text he/she are reading it.

To know whether a learner is good at reading and comprehending the English texts, the writer needed to develop a reading evalution instrument. The development of reading instrument is designed to measure the learners' comprehension mastery of English texts.

Evaluation is a systematic determination of a subject's merit, worth and significant, using criteria which is governed by a set of standards. It can assist an organization, program, project or any other interventions or initiative to assess aims, realizable concepts/proposals, or some alternative, to help in decisionmaking; or to ascertain the degree of achievement or value in regard to the aims and objectives and the results of such action that has been completed. The primary purpose of evaluation is to gain the insight into prior or existing initiatives, is to enable reflection and assist in the identification of future changes.

Evaluation owns many purposes. Before assessing a program, it is critical to consider who is most likely to need and to use the information that will be obtained and for what purposes. These reasons cut across the three types of evaluation just mentioned. The degree which the perspectives of the most important potential users are incorporated into an evaluation design will determine the usefulness of the effort.

\section{Method}

The method used to develop the evaluation instrument is conducted by applying a research and development. The writer applied formative research as the research design. It means that the writer started to develop the evaluation 
instrument by using two kinds of texts, they are: Narrative and Describtive text. The following stages are developmental steps of the evaluation instrument, as follows:
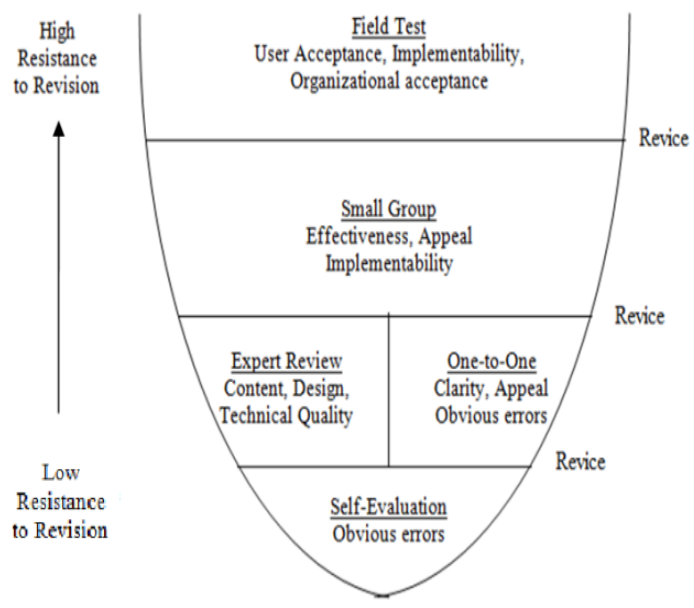

Design formative research

(Tessmer, 1993. p.35)

Based on the instructional design flowchart above that the writer develop a proto-type (initial product) first by modifying the previous evaluation instrument that has been applied before by the previous teacher who taught reading comprehension four to the students. So far, the development process follow the following procedures as follows: self evaluation step, expert review and one-to-one step, small group and field test to find final product.

\section{Research Method: Stage 1 \\ Product Design}

This prototype is designed based on the modified evaluation material which has been used previously by another teacher at the same level on measuring the students' reading comprehension. It is gotten by self evaluation, expert review and one to one, small group and field test. By doing the small group the researcher will get the result of it and it will be revised second product. It will produce the third prototype.

\section{Research Subject}

The subjects of this research are the student State of Junior High School 6 Metro on VII (seventh) class. Respondents are gotten by using cluster random sampling. It is chosen randomly without using specific criterion. It is necessary to do small group. After getting six respondents, the students will get the second prototype and they will get questionnaire 


\section{Types of Data}

The researcher uses two kinds of questionnaires to get the data, they are as follows:

1. Readability Instrument.

2. Implement Ability Instrument

\section{Data Collecting Instrument}

According to Sugiyono (2008: p.224) says "Data collecting is the important step in research because the main purpose is to get the data". It means that instrument is a tool to get the data in the research. Without data collecting the researcher can not get the data which fullfill requirements.

Based on the explanation above, in relation to the objectives of the research, the researcher will employee questionnare readability and implementability in reading skill to get the data needed. The test has designed to measure the effect of specific teaching. Questionnare readability and implementability in reading skill will be write or performances, in which students were asked to, select one of the topics given. Beside, questionnaire is helped to know student response of development evaluation.

The researcher will use experts' opinion, in order to repair evaluation of CTL. There are two kinds of questionnaires, they are readability and implement ability. Readability will be use to measure the sightings and attractiveness of the evaluation itself. Otherwise, implement ability will be applied to measure the level of the evaluation is too difficult, too easy or mediocrity and whether the evaluation is suitable with standard competence or not. From the explanation above the researcher uses triangulation like expert s' opinion or expert judgment, readability instrument, and implement ability instrument.

\section{Data Analysis Technique}

This stage of analyzing data includes:

\section{Analyzing Readability Questionnaires}

After getting the data from the field, the researcher will find the weakness 
and the strengthen of evaluation. Then, the researcher also use some will count the frequency of questionnaire to see the data

\section{Analyzing Implementability \\ Questionnaire}

The purpose of this analysis is to know how far this product can be applied. It is also used to revise the product in order to get the better product. This questionnaire will be used by the teacher. The researcher also will get the comment from the teacher about the weakness of the product to repair, revise, and develop the product. In this case the teacher will give some comment for the content of evaluation. And the researcher will use this questionnaire to get responds from the teacher

\section{Research Method: Stage 2}

\section{Product Design}

This prototype is designed based on contextual teaching learning especially for reading skill. It is gotten by self evaluation, expert review and one to one, small group and field test. By doing the small group the researcher will get the result of it and it will be revised second product. It will produce the third prototype.

\section{Research Subject}

The subjects of this research are the student of State Junior High School 6 Metro. It is gotten by snowballing technique. It is chosen randomly without using specific criterion. It is necessary to do field test. The researcher will use one class and the students around 32 people. The students will get the second prototype after that they will get questionnaire

\section{Types of Data}

The researcher uses two kinds of questionnaires to get the data readability instrument. Implement ability instrument, data of the result score of evaluation product, and daily score of students in class VII.1. Data will be gotten collective as the basic to revise the product and develop evaluation based on CTL especially in greeting. 


\section{Data Collecting Instrument}

This is part of field test. The researcher will use questionnaire of readability and implement ability like in one-to-one and small group. The researcher employs test of reading to get the data needed. The test has designed to measure the effect of specific teaching. The reading test will be write or performances, in which students were asked to, select one of the topics given and they show their work. Beside, questionnaire is helped to know student response of development evaluation.

Reading will be conducted orally, the students will choose what kind of the topic that they want then the researcher will know students' responding and understanding. The researcher will get two main data, the first is daily score from the teacher as the expert in the field and the second is the score of the field test product focus on text from students as the respondent. All of the data will be combine with the last revision to be done.

\section{Data Analysis Technique}

To get the data the researcher use the three main instruments analyzing of readability, analyzing of implement ability, daily score of the students, and students's reading performing based on the result in the field test.

Based the result of scoring above from questionnaire to know readability and implementability of evaluation based content based on CTL refers to Sugiono (2008. p95)

\section{Result of Product Designing}

Product is shown to student may got the material. Students get warm brains or brain storming to lure the extent of their basic knowledge. Students will have some questions and give comment about the product. How far students know or understand about the product applied. Evaluation English learning material.

Product design of this research attempts to develop evaluation for English evaluation instrument on reading based on contextual teaching learning. It was reviewed by expert and one-to-one. Experts review 
suggested perfecting design before published. On the other hand from one-to-one step by student is gotten information that they accept the evaluation product without any further obstacles so far.

Based on expert review and one-toone step analysis above, the researcher revise the product by reflect what should student need to know about the goal or function of product as English evaluation based on contextual teaching learning is design development for evaluation. Although the product is easy to follow the researcher stay to keep student implementing.

\section{Result of Validity}

Researcher uses content validity as decided of the questionnaires of evaluation validation for reading based on contextual teaching learning. The researcher found each item is valid. The result of validity can be seen in the appendix 11. On the other hand, the questionnaire has high score.

Based on the calculation, it is known that $r_{x y}$ is 0,76 . The result of reliability can be seen in the appendix 12 on 69 Because of that, $r_{x y}$ is in high category. It means that the reliability of questionnaires is high.

\section{Result of the First Product Testing}

First product testing is in this case as product testing is called small group testing. Those tests include five non respondent students. The respondents instruct to finish and give comment for evaluation product based on contextual teaching learning. After getting test, the respondents get readability. It dispraises five aspects names font size until content and messages. Each aspect as indicator in the questionnaires is expected to get suggestions concern with the implementability instrument.

Most of the result of the components in readability were high except the layout of the product, it needed to repair and improve. Number one was about the font size of the second prototype. And the researcher needs adding content and messages from the material on the product of evaluation. 
Two of five students give three and three student give for for the score of the font size. And the result was $72 \%$, it means that the students could read word clearly. Number two is about election which was served in the prototype. The result of number two of the questionaire was $60 \%$. It means that the students had good respond for the prototype. Number three told about atrractiveness, the students also had good repond for the product it was $68 \%$. Number four told about the instruction of the evaluation. The result of it was $64 \%$, it means that the instruction were easy to understand. Number five was about the content of information and the result was $64 \%$.

\section{Revision on the First Product Testing}

According to result of testing product of evaluation based on contextual teaching learning, researcher revises the product which concerns in content and messages indicator that has lowest score. Researcher adding some topic variety in the product. Revising of product is adding messages by adding character or story in the product. Beside that, researcher deletes repetition information about the product of evaluation reading.

Beside, implementation of the evaluation product did not get troubles. The questionnaires say that respondent give good response. It means that researcher will not revise for implementability

\section{Result of the Second Product \\ Testing}

Researcher did test after getting revision from small group. This second product testing is called field test that involves thirty five students as respondent. After getting test, the respondents get readability and implementability questionnaire. The result of readability questionnaire says that all components are shown great score. Font size indicator show very high category and other indicator in the high score. It means that each indicator in readability instrument of reading evaluation is good. The result of lay out was $84 \%$, it means that the students had 
interested in it. And then, the result of evaluation instrument on reading skiil was $76 \%$. From these calculation above, it can be concluded that the third field test was succes because all of result are $>70 \%$.

\section{Revision of the Second Product}

\section{Testing}

Based on result of testing product of evaluation based on contextual teaching learning, researcher revise the product which concern in all aspect in indicator that have lowest score. The content and message indicator is still there. The point of revision is same like previous but make the product be perfect. Revising a lot is not needed.

On the other hand, implementation of the evaluation product did not get troubles. The questionnaires say that respondent give good response. It means that the researcher does not revise for implementability. It means that the question in evaluation based on contextual teaching learning can be used. From explanation below, question in the evaluation for reading based on contextual teaching learning is not needed revision.

\section{Refinement of the Second Product}

Based on many revision in some testing that develop this evaluation for the evaluation for reading based on contextual teaching learning was made as perfecting design before published. On one-to-one step by student is gotten information that they accept the evaluation product.

Based on the data from small group test, researcher adds some topic variety in the product. Revising of product is adding messages by adding character or story in the product. Beside that, researcher deletes repetition information about the product of evaluation reading. Beside, implementation of the evaluation product says that respondent give good response. It means that researcher will not revise for implementability

In field test, researcher applied product in the class. The point of revision is same like previous but make the product be perfect. Revising a lot is not needed. On the 
other hand, implementation of the evaluation product did not get troubles. It means that the question in evaluation based on contextual teaching learning can be used. From explanation below, question in the evaluation for reading based on contextual teaching learning is not needed revision.

\section{Conclusion}

Referring to the outcome of the try out that, the writer revised product above. The writer revised the product by modifying the previous evaluation instrument and applying some try out. what should student need to know about the goal or function of product as English learning material based on contextual teaching learning is design development for evaluation. Although the product is easy to follow the researcher stay to keep student implementing. The result of readability questionnaire says that almost all components belong to high score category. Behind all, indicator of content and message get enough categories. Although it is not destructs other aspect of indicator. It means that the researcher needs adding content and messages from the material on the product of evaluation. implementation of the evaluation product did not get troubles. The questionnaires say that respondent give good response. It means that researcher will not revise for implementability. Implementation improving which from implementability questionnaire shows good response from student. The questionnaire says that the respondents interest with evaluation that may improve their reading skill. , implementation of the evaluation product did not get troubles. The questionnaires say that respondent give good response. It means that the researcher does not revise for implementability. It means that the question in evaluation based on contextual teaching learning can be used. From explanation below, question in the evaluation for reading based on contextual teaching learning is not needed revision. 